\section{Midbuccal Canals of Maxillary Molars Evaluated by Cone-Beam Computed Tomography: Endodontic Management of Two Cases}

Manoel Brito-Júnior', Gil Moreira-Júnior ${ }^{2}$, João Américo Normanha ${ }^{3}$, André Luis Faria-e-Silva ${ }^{4}$, Carla Cristina Camilon ${ }^{1}$ Ricardo Novak Savioli ${ }^{1}$, Paulo César Saquy ${ }^{1}$

\begin{abstract}
Maxillary molars present variable root canal and root morphologies. This report describes the endodontic management of two cases of midbuccal canals found in maxillary molars. Midbuccal canals were present in a maxillary first molar with a single buccal root (Case 1), and in a maxillary second molar with three buccal roots (Case 2). An assessment of the internal configuration of these teeth was performed using cone-beam computed tomography (CBCT). Magnification with a dental operating microscope, surgical loupes, and the use of an endodontic explorer enabled the identification of the midbuccal canal orifices. The root canals in both cases were chemomechanically prepared and filled. Postobturation radiographic images revealed four (one midbuccal, two mesiobuccal and one palatal) and five (one midbuccal, two mesiobuccal, one distobuccal and one palatal) root canals, which were filled in Cases 1 and 2, respectively. Complex canal configurations of maxillary molars including the presence of midbuccal canals were presented. CBCT was a valuable tool in this diagnosis, as it provided a precise description of these unusual anatomical variations.
\end{abstract}

\author{
'Inter-institutional PhD \\ Program, UNIMONTES - State \\ University of Montes Claros, \\ Montes Claros, MG, Brazil \\ ${ }^{2}$ Dental School of University of \\ Itaúna, Itaúna, MG, Brazil \\ ${ }^{3}$ Department of Dentistry, \\ UNIMONTES - State University \\ of Montes Claros, Montes \\ Claros, MG, Brazil \\ ${ }^{4}$ Department of Dentistry, - \\ UFS - Federal University of \\ Sergipe, Aracaju, SE, Brazil
}

Correspondence: Prof. Dr. Manoel Brito Júnior, Avenida Rui Braga s/n, Vila Mauricéia, 39401-089 Montes Claros, MG, Brasil. e-mail: manoelbritojr@ gmail.com Tel: +55-38-3229-8284

\section{Introduction}

Successful endodontic therapy depends on an accurate diagnosis, adequate chemomechanical debridement and complete filling of root canals. A detailed knowledge of the anatomic features of the root canal system is therefore essential, particularly in teeth that present complex and variable internal configurations $(1,2)$. If neglected, these anatomical variations may compromise the endodontic therapy outcomes.

The first and second maxillary molars show important variations in their number of roots and root canals. The presence of three roots (two buccal and one palatal), and either three or four root canals are frequently observed in these teeth $(3,4)$. However, the presence of additional root canals has been reported for mesiobuccal, distobuccal and palatal roots (5-9). Maxillary first molars with a single (10) two or four roots (11-13), and maxillary second molars with additional buccal or palatal roots have also been described (14-16). In these scenarios, the presence of a midbuccal canal is an extraordinary variation, which has been rarely reported in maxillary first molars (17), as this canal was mainly found in maxillary second molars $(16,18,19)$.

Recently, the use of three-dimensional (3D) imaging techniques, such as cone beam computed tomography (CBTC) was widely used in endodontic therapy (20), enabling verifying the number and location of root canals (21). The 3D images provided by CBCT offer more detailed information regarding root canal anatomy than the traditional radiographic images $(22,23)$. This report describes the endodontic management of two cases of midbuccal (Mid B) canals found in a maxillary first molar with a single buccal root and in a maxillary second molar with three buccal roots. CBCT was used as a diagnostic tool in both cases.

\section{Case Report}

\section{Case 1}

A 62-year-old woman with a noncontributory medical history complaining of pain episodes in the right maxillary first molar was referred to our clinic for endodontic treatment. During clinical examination the tooth presented a resin-based composite restoration and tenderness to vertical percussion, but not to palpation. Swelling or sinus tract were not observed. Pulp testing using a cold spray (Endo-Ice; The Hygienic Corporation, Akron, OH, USA) generated an intense pain, which was slow to abate. A periapical radiograph revealed calcification of the root canals and a restoration close to the pulp horns (Fig. 1A). Radiographic evaluation did not reveal any variation in the root canal anatomy. The diagnosis was determined as symptomatic irreversible pulpitis. A treatment plan of root canal treatment of the tooth was presented to the patient and was consented.

While the patient was under local anesthesia and with rubber dam, an access opening was performed and the root canal entrances were explored using an endodontic explorer 
(Odous, Contagem, MG, Brazil). Two root canal orifices (one buccal and one palatal) were detected. After further inspection of the pulpal floor using a surgical operating microscope (DF Vasconcelos, São Paulo, SP, Brazil), two more canal orifices were identified closer to the buccal orifice. An ultrasonic device (Gnatus, Ribeirão Preto, SP, Brazil) with an ultrasonic tip (TU17; Trinity, São Paulo, SP, Brazil), was used to remove excess dentin, facilitating the procedure. Three buccal orifices (mesiobuccal, midbuccal and distobuccal) and one palatal orifice were located. It was decided to perform CBCT imaging of the tooth to verify this unusual morphology. The canals were dressed with an antibiotic-corticosteroid product (Otosporin; Farmoquimica S/A, Rio de Janeiro, RJ, Brazil). The tooth was then provisionally sealed with a non-eugenol temporary filling material (Cimpat; Septodont, Saint Maur, France).

A CBCT scan (Next Generation i-CAT; Imaging Sciences International, Hatfield, PA, USA), was obtained from the maxillary right first molar region with exposure parameters of $120 \mathrm{kV}$ and $5.0 \mathrm{~mA}$. The images were reconstructed at $0.25-\mathrm{mm}$ thickness increments. CBCT axial images confirmed the presence of three buccal (mesiobuccal, midbuccal and distobuccal) canals, and one palatal canal

(Fig. 2A). Coronal images corroborate the presence of three independent buccal canals (Fig. 2B).

At the second appointment, the tooth was reopened under local anesthesia and a rubber dam. The intracanal dressing was removed after flushing with a $2.5 \%$ sodium hypochlorite $(\mathrm{NaOCl})$ solution. Based on the root length, established at preoperative radiograph, all root canals were explored with sizes 8 and $10 \mathrm{~K}$-files, and \#1 to \#3
PathFile rotary instruments (Dentsply-Maillefer, Ballaigues, Switzerland). An electronic apex locater (Novapex; Forum Technologies, Rishon Lezion, Israel) was used to determine the working length, which was confirmed by a periapical radiograph (Fig. 1B). Formatting of all canals was completed using a R25 reciprocation single-file (VDW GmbH, Munich, Germany). Preparations were performed under irrigation with a $2.5 \% \mathrm{NaOCl}$ and a $17 \%$ EDTA solution was used as the final irrigant for smear layer removal. The canals were then dried with absorbent points (Dentsply-Maillefer). The root canals were filled using the warm vertical condensation technique with non-standardized gutta-percha cones (Odous) and Sealer 26 (Dentsply, Petrópolis Ind. e Com. Ltda, RJ, Brazil) (Figs. 1C and D). The tooth was then provisionally sealed as described previously and postobturation CBCT images were acquired. Axial images showed the four rootfilled canals (Fig. 2C), while coronal images displayed three root-filled buccal canals, including the midbuccal canal (Fig. 2D). The patient was then referred for permanent restoration of the tooth.

Patient gave informed consent for report of the case and publication of the clinical images.

\section{Case 2}

A 23-year-old male patient was referred to our clinic for endodontic treatment of the right maxillary second molar. His family dentist had performed an emergency treatment, consisting of caries removal and a temporary restoration with glass ionomer cement. After 3 days, the patient came complaining of spontaneous pain. Medical history was non-contributory. A clinical examination of the tooth
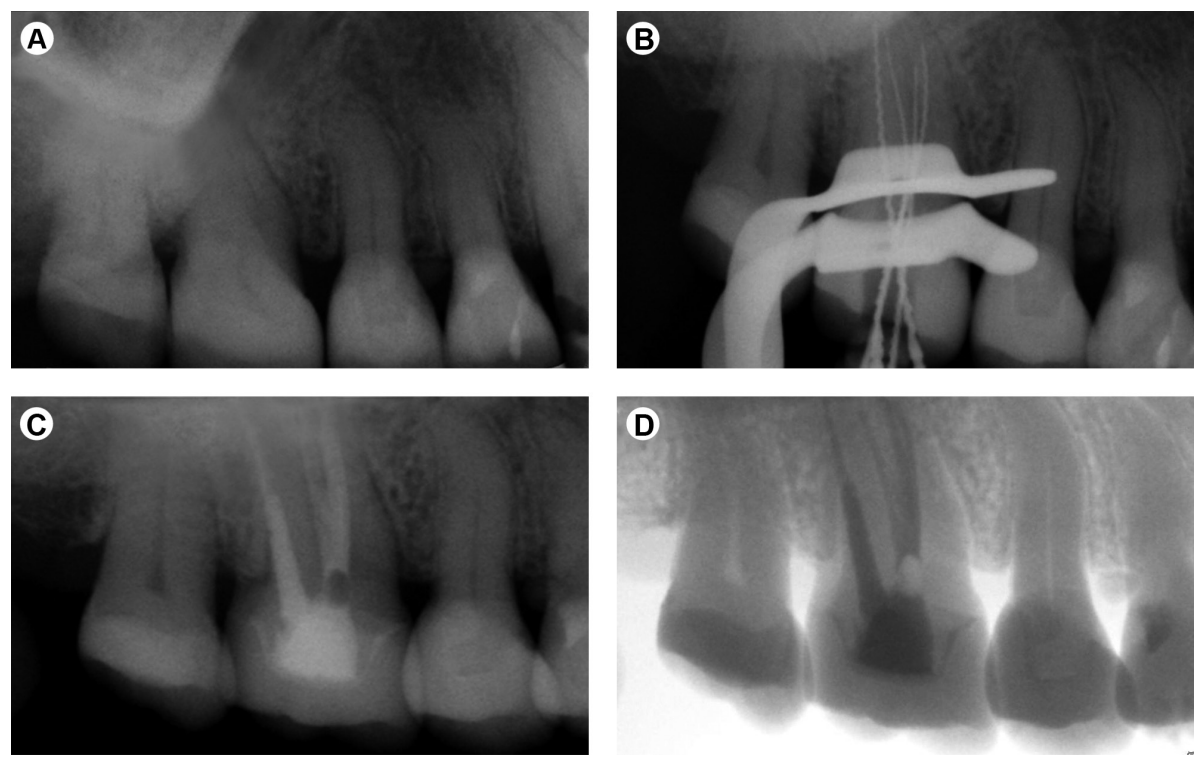

Figure 1. Case 1. A: Preoperative radiograph of the maxillary right first molar. B: Radiograph for working length determination. C: Postobturation radiograph. D: Grayscale-inverted postobturation radiographic image showing four root-filled canals (three buccal and one palatal). 
revealed no swelling or sinus tract, and a slight response to percussion and palpation. A diagnosis of symptomatic irreversible pulpitis was confirmed by a cold pulp test (Endo-Ice). The preoperative periapical radiograph showed no signs of periapical infection (Fig. 3A). A convergence of the roots and an additional root in the mesial aspect of tooth were observed at an initial radiographic evaluation. The patient consented to the proposed root canal treatment.

After local anesthesia, a rubber dam was placed, and

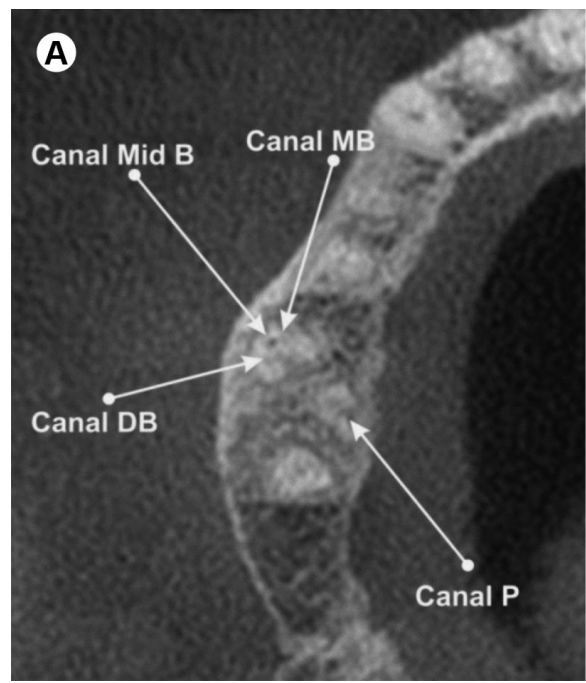

the pulp chamber was exposed. The access opening was refined and four root canal orifices (two mesiobuccal, one distobuccal and one palatal) were detected using an endodontic explorer (Odous) on the pulpal floor. Upon repeating this inspection, using a $4.5 \times$ binocular loupe (BioArt Equipamentos Odontológicos, São Carlos, SP, Brazil), the tip of the explorer identified an additional buccal canal orifice. The excess dentin over this orifice was removed with an ultrasonic tip, as described in Case 1. The additional canal

Figure 2. Case 1. A: CBCT axial image of the maxillary right first molar. Presence of three buccal (MB, mesiobuccal, Mid B, midbuccal and DB, distobuccal) canals, and one palatal (P) canal. B: CBCT coronal image showing the three buccal canals.
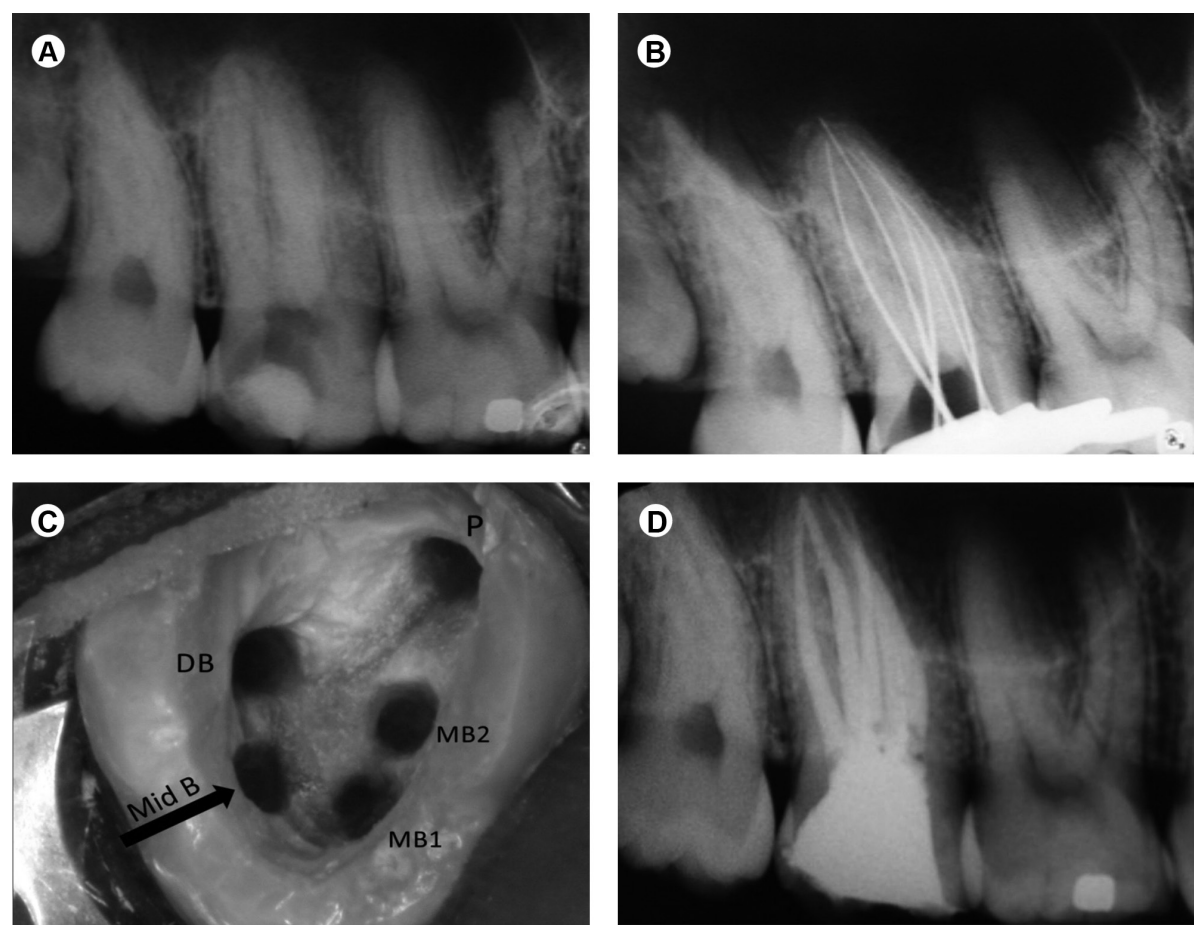

Figure 3. Case 2. A: Preoperative radiograph of the maxillary right second molar. B: Radiograph for working length determination. C: Access opening after root canal preparation showing five root canal orifices (MB1, mesiobuccal 1, MB2, mesiobuccal 2, Mid B, midbuccal, DB, distobuccal and P, palatal). D: Postobturation radiograph. 
was located more central to the first mesiobuccal and the distobuccal canals, characterizing it as a midbuccal canal. All root canals were explored using sizes 10 and $15 \mathrm{~K}$-files based on the root length established at the preoperative periapical radiograph, under abundant irrigation with $2.5 \%$ $\mathrm{NaOCl}$. The entire pulp tissue was carefully removed from the root canals. As a CBCT examination was requested to evaluate more clearly the internal anatomy, the endodontic procedures were finalized in this appointment. Thus, the root canals were dressed and the tooth was provisionally sealed as described in Case 1.

The CВCT scan focused on the maxillary right second molar was acquired using similar exposing and reconstructing parameters to those described in Case 1. CBCT axial images showed presence of three distinct buccal roots with four canals (two mesiobuccal, one midbuccal and one distobuccal), and one palatal root with one canal (Fig. 4A). A CBCT coronal image confirmed the independent course of the midbuccal canal (Fig. 4B).

After seven days the patient returned for a second appointment. The temporary restoration and the intracanal dressing were removed under local anesthesia and rubber dam. All root canals were prepared in a crown-down $\vec{s}$ method using ProTaper NiTi rotary instruments (MailleferDentsply). Electronic root canal lengths were determined using an apex locater (Novapex). The radiograph taken to confirm the working lengths also showed five root canals (Fig. 3B). A clinical view of the access opening after root canal preparation showed five well-defined root canal orifices, including the midbuccal canal (Fig. 3C). The irrigation protocol was the same as used in Case 1. The canals were dried and filled with a zinc oxide-eugenolbased sealer (Endofill, Dentsply, Petrópolis, RJ, Brazil) and non-standardized gutta-percha cones (Odous), using cold lateral condensation. A temporary filling was placed and a postoperative radiograph was taken to assess the quality of the root canal fillings (Fig. 4D). The patient was subsequently referred to his dentist for restorative treatment.

Patient gave informed consent for report of the case and publication of the clinical images.

\section{Discussion}

The identification and treatment of complex root canal systems represents a permanent challenge for clinicians. In the present report, different configurations of the midbuccal canal were observed in maxillary molars. It has been shown that $0.3 \%$ of maxillary second molars presented a midbuccal root canal. However, presence of this canal has not been found in maxillary first molars (16). While several case reports depicted a variety of canal morphologies in maxillary molars, only a minority described the presence of midbuccal canals (17-19). In addition, endodontic treatment failure caused by a missed midbuccal canal in a second maxillary molar has also been reported (19).

The diagnosis of anatomic variations in root canals can be impaired by the diagnostic method used. A periapical radiograph is the most common method used to assess the configuration of root canal systems during endodontic treatments. Additionally, roots and root canals can be visualized by a detailed radiographic examination, varying the horizontal angle $(3,19)$. However, radiographs produce a 2-dimensional image of 3-dimensional objects. This prevents a complete understanding of root morphology and canal anatomy (2). In the present report, preoperative radiographs provided limited information regarding the anatomical variations of the maxillary molars in both cases.

CBCT is an imaging modality used to improve the assessment of root canal systems $(8,10,13-17)$. As CBCT delivers three-dimensional views, it offers superior diagnostic performance over conventional radiographic images when determining the presence of anatomic variations $(22,23)$. As such, the higher accuracy of CBCT imaging facilitates the visualization of additional root canals that could be missed, compromising the success
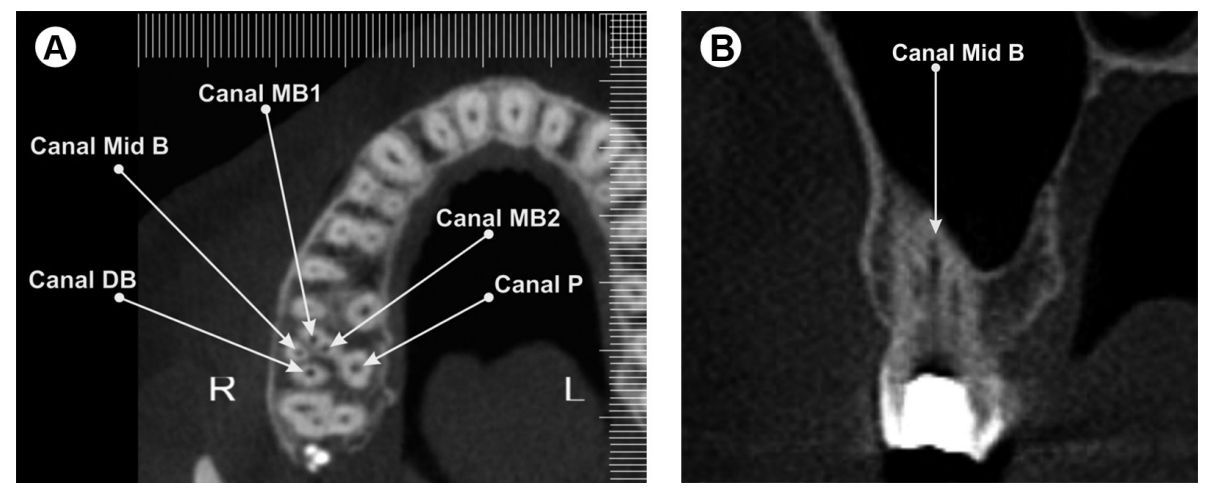

Figure 4. Case 2. A: CBCT axial image of the maxillary right second molar showing four buccal (MB1, mesiobuccal 1, MB2, mesiobuccal 2, Mid B, midbuccal and DB, distobuccal) canals and one palatal (P) canal. B: CBCT coronal image showing the midbuccal canal. 
of treatment. However, due to its high-cost, use of CBCT for endodontic treatment remains limited, and it is only employed when a diagnosis is still uncertain after conventional radiography (20). In the cases reported herein, CBCT scans confirmed the presence of midbuccal canals, as they enabled the precise description of this unusual anatomical variation in maxillary molars.

The experience of the clinician is important when identifying anatomic variations in root canal systems. During the clinical exploration of root canal orifices, an unusual canal was detected in both reported cases. The use of a dental microscope or surgical loupes facilitated this diagnosis. The magnified view of the operating field provided by these devices increases the likelihood of locating hidden canals $(24,25)$. In the present report, endodontic treatments were performed by endodontists with more than 10 years experience with the use of a microscope (Case 1) or loupes (Case 2). In addition, a careful examination of the pulpal floor with an endodontic explorer, and the use an ultrasonic tip to remove the dentin coverage over the midbuccal canals were important procedures to ensure successful treatment outcomes $(2,23)$.

The cases reported demonstrate that awareness of anatomic variations in the root canal systems of maxillary molars leads to more successful endodontic treatments. Furthermore, the use of more accurate diagnostic tools, such as CBCT, facilitates the identification of uncommon anatomic variations, enhancing diagnosis and treatment.

\section{Resumo}

Molares superiores apresentam morfologias radiculares e canais radiculares variáveis. Este relato de caso descreve o manejo endodôntico de dois casos de canais mésio-centrais (MC) encontrados em molares superiores. Canais MC estavam presente em um primeiro molar superior com uma única raiz vestibular (Caso 1), e em um segundo molar com três raizes vestibulares (Caso 2). Uma avaliação da configuração interna destes dentes foi realizada usando tomografia computadorizada de feixe cônico (TCFC). Ampliação com microscópio operatório odontológico, lupas cirúrgicas e o uso de um explorador endodôntico possibilitaram a identificação dos orifícios dos canais MC. Os canais radiculares dos dois casos foram preparados e obturados. Imagens radiográficas pós-obturação revelaram quatro (um MC, dois mésio-vestibulares e um palatino) e cinco (um MC, dois mésio-vestibulares, um disto-palatino e um palatino) canais radiculares, que foram obturados nos Casos 1 e 2, respectivamente. Configurações complexas de canais em molares superiores, incluindo a presença de canais MC foram apresentadas. TCFC foi uma ferramenta útil no diagnóstico e propiciou uma descrição precisa destas variações anatômicas incomuns.

\section{References}

1. Vertucci FJ. Root canal morphology and its relationship to endodontic procedures. Endod Topics 2005; 10:3-29.

2. Cantatore G, Berutti $E$, Castellucci A. Missed anatomy: frequency and clinical impact. Endod Topics 2009;15:3-31.

3. Ingle JI, Bakland L, eds. Endodontics, 5th Edition. Hamilton Ontario: BC Decker, 2002.

4. Cleghorn BM, Christie WH, Dong CC. Root and root canal morphology of the human permanent maxillary first molar: a literature review. J Endod 2006;32:813-821.
5. Hülsmann M. A maxillary first molar with two disto-buccal root canals. J Endod 1997; 23:707-708.

6. Ferguson DB, Kjar KS, Hartwell GR. Three canals in the mesiobuccal root of a maxillary first molar: a case report. J Endod 2005;31:400-402.

7. Albuquerque DV, Kottoor J, Dham S, Velmurugan N, Abarajithan $M_{1}$ Sudha R. Endodontic management of maxillary permanent first molar with 6 root canals: 3 case reports. Oral Surg Oral Med Oral Pathol Oral Radiol Endod 2010;110:e79-e83.

8. Kottoor J, Hemamalathi S, Sudha R, Velmurugan N. Maxillary second molar with 5 roots and 5 canals evaluated using cone beam computerized tomography: a case report. Oral Surg Oral Med Oral Pathol Oral Radiol Endod 2010;109:e162-165.

9. Versiani MA, Pécora JD, Sousa-Neto MD. Root and root canal morphology of four-rooted maxillary second molars: A microcomputed tomography study. J Endod 2012;38:977-982.

10. Ioannidis K, Lambrianidis T, Beltes P, Besi E, Malliari M. Endodontic management and cone-beam computed tomography evaluation of seven maxillary and mandibular molars with single roots and single canals in a patient. J Endod 2011;37:103-109.

11. Fava LR. Root canal treatment in an unusual maxillary first molar: a case report. Int Endod J 2001;34:649-653.

12. Ma $\mathrm{L}$, Chen J, Wang $\mathrm{H}$. Root canal treatment in an unusual maxillary first molar diagnosed with the aid of spiral computerized tomography and in vitro sectioning: a case report. Oral Surg Oral Med Oral Pathol Oral Radiol Endod 2009;107:e68-e73.

13. Kottoor J, Velmurugan N, Ballal S, Roy A. Four-rooted maxillary first molar having $\mathrm{C}$-shaped palatal root canal morphology evaluated using cone-beam computerized tomography: a case report. Oral Surg Oral Med Oral Pathol Oral Radiol Endod 2011;111:e41-e45.

14. Neelakantan , Subbarao C, Ahuja R, Subbarao CV, Gutmann JL. Conebeam computed tomography study of root and canal morphology of maxillary first and second molars in an Indian population. J Endod 2010;36:1622-1627.

15. Zhang $R$, Yang $H, Y u X$, Wang $H, H u T$, Dummer PM. Use of CBCT to identify the morphology of maxillary permanent molar teeth in a Chinese subpopulation. Int Endod J 2011;44:162-169.

16. Kim Y, Lee SJ, Woo J. Morphology of maxillary first and second molars analyzed by cone-beam computed tomography in a Korean population: variations in the number of roots and canals and the incidence of fusion. J Endod 2012;38:1063-1068.

17. Kottoor J, Nandini S, Velmurugan N. Maxillary first molar with three buccal roots evaluated with cone-beam computed tomography: a rare case report. Gen Dent 2012;60:e404-e407.

18. Zmener 0, Peirano A. Endodontic therapy in a maxillary second molar with three buccal roots. J Endod 1998;24:376-377.

19. Jafarzadeh $H$, Javidi $M$, Zarei $M$. Endodontic retreatment of a maxillary second molar with three separate buccal roots. Aust Endod J 2006;32:129-132.

20. Durack $\mathrm{C}$, Patel $\mathrm{S}$. Cone beam computed tomography in endodontics. Braz Dent J 2012; 23:179-191.

21. Michetti J, Maret D, Mallet JP, Diemer F. Validation of cone beam computed tomography as a tool to explore root canal anatomy. J Endod 2010;36:1187-1190.

22. Matherne RP, Angelopoulos C, Kulild JC, Tira D. Use of cone-beam computed tomography to identify root canal systems in vitro. J Endod 2008;34:87-89.

23. de Toubes KM, Côrtes MI, Valadares MA, Fonseca LC, Nunes E, Silveira FF. Comparative analysis of accessory mesial canal identification in mandibular first molars by using four different diagnostic methods. J Endod 2012;38:436-441.

24. Corcoran J, Apicella MJ, Mines P. The effect of operator experience in locating additional canals in maxillary molars. J Endod 2007;33:15-17.

25. Karapinar-Kazandag M, Basrani BR, Friedman S. The operating microscope enhances detection and negotiation of accessory mesial canals in mandibular molars. J Endod 2010;36:1289-1294.

Received August 30, 2013 Accepted November 22, 2013 